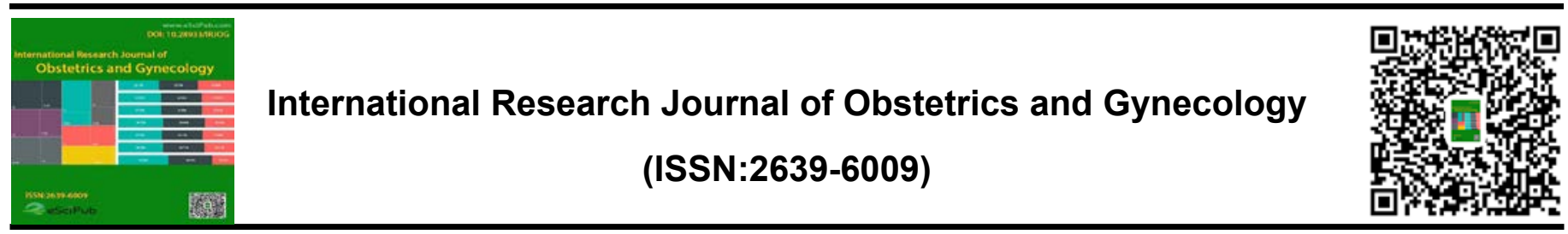

\title{
Genital Prolapse on Pregnancy: Case Study and Literature Review
}

\author{
Biaye B, Barry A, Gassama O, Cisse ML, Diouf AA, Niang MM, Cisse M, Diouf A, Diakhat A, \\ Fall KBM, Gueye K, Moreira PM, Diouf A, Moreau JC.
}

Aristide Le Dantec hospital in Dakar, Senegal

\begin{abstract}
Genital prolapse is a common gynecological condition, but it is exceptional during pregnancy. It can be pre-existent or else manifest in the course of pregnancy. Complications resulting from prolapse of the uterus in pregnancy vary from minor cervical infection to spontaneous abortion, and include preterm labor and maternal and fetal mortality as well as acute urinary retention and urinary tract infection. Moreover, affected women may be at particular risk of dystocia during labor that could necessitate emergency intervention for delivery.

We report the case of a third third-generation 32-year-old third gesture second pare with no particular health history. The last two pregnancies proceeded normally with stage 2 genital prolapse occurring in the second trimester of pregnancy that was aggravated by abdominal expression during childbirth.
\end{abstract}

Keywords: genital prolapse, pregnancy, complications, abdominal expression
${ }^{*}$ Correspondence to Author:

Biaye B

Aristide Le Dantec hospital in Dakar, Senegal

How to cite this article:

Biaye B, Barry A, Gassama O, Cisse ML, Diouf AA, Niang MM, Cisse M, Diouf A, Diakhat A, Fall KBM, Gueye K, Moreira PM, Diouf A, Moreau JC. Genital Prolapse on Pregnancy: Case Study and Literature Review. International Research Journal of Obstetrics and Gynecology, $2019,2: 9$

\section{eScîPub}

eSciPub LLC, Houston, TX USA.

Website: https://escipub.com/ 


\section{Introduction}

Genital prolapse is a permanent, transient abnormal migration of one or more pelvic organs form and / or the location of the vaginal walls, up to their externalization through the urogenital cleft. Traumatic lesions of levers Anus, denervation of pelvic floor musculature, abnormalities pelvic biostatistics, obesity, chronic pulmonary pathology, rick bending anomalies, Corticotherapy, pelvic surgery, chronic constipation are the elements underlying genital prolapse. It is a functional pathology affecting the quality of life of many women. He rather reaches the elderly woman but does not spare young patients. Genital prolapse is a major public health problem because of its frequency, cost and impact important on the quality of life with repercussions on the urinary, sexual and digestive function [1].

Genital prolapse during pregnancy is rare with an estimated incidence of 1 per 10,000 to 15,000 deliveries [1]. Complications of this condition include patient discomfort, cervical desiccation and ulceration, urinary tract infection, acute urinary retention, abortion, premature labor, maternal and fetal sepsis [2].

We report the case of a patient with secondary genital prolapse aggravated by an abdominal expression at the stage of an expulsive labor.

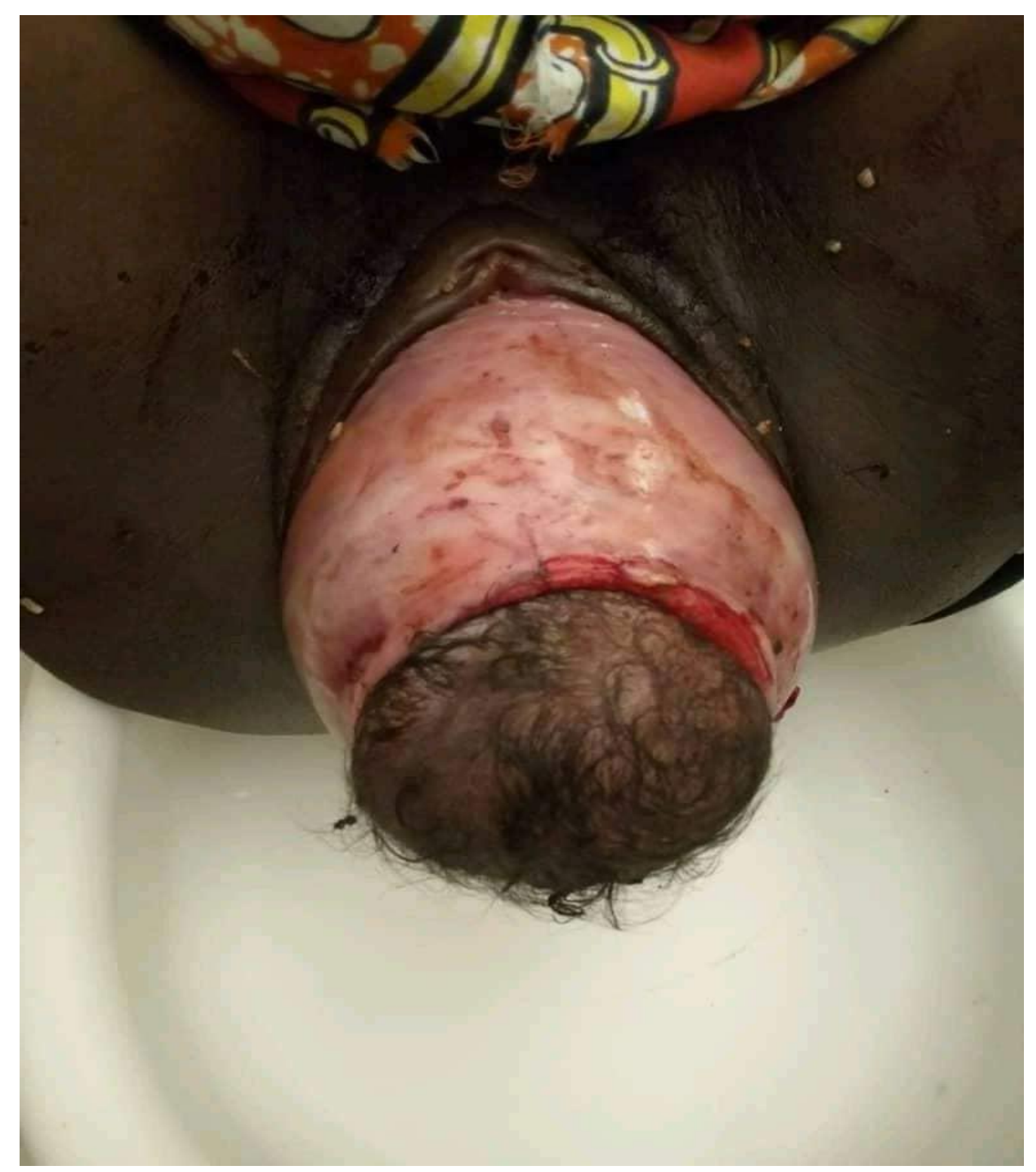

Figure 1: Stage 3 genital prolapse on pregnancy at the active phase of labor 


\section{Observation}

It was a 32-year-old third gesture second pare with no particular health history. The last two pregnancies proceeded normally without any notion of obstructed labor or instrumental extraction. During this last pregnancy, monitored by a midwife in a health post, the prolapse of stage 2 located at the uterus level, would have appeared in the second trimester. During the pregnancy, we noticed an episode of premature labor on a background of urinary tract infection.

The patient came to our service for health referral during the second phase of her labor with a notion of abdominal pain during pushing efforts. This last action had caused the complete externalization of the prolapse.

At admission, the patient was in an expulsive phase of labor with good uterine dynamics. The genital prolapse involved the third floors and was rated stage 3 .

Thirty minutes later she gave birth to a new female born weighing $2900 \mathrm{~g}$ with a 9/10 APGAR score. There was a left lateral cervical tear of 4 centimeters, which was well repaired and the postpartum care were simple.

\section{Discussion}

Genital prolapse is a common condition; however, the occurrence of prolapse in a pregnant woman is an exceptional situation. A few rare cases of genital prolapse have been published.

\section{Pathophysiology}

It is classically accepted that the pelvi-perineal anatomy of the woman is managed by a triple system whose integrity is essential to ensure a correct balance: a suspensive system consisting of ligamentous structures, a cohesive system made up of fascia and a system of muscular support, formed mainly of the elevating muscles of the anus. These systems must be sufficiently flexible to allow adaptation to pregnancy and childbirth; they must also be sufficiently resistant to maintain a static effective pelvic especially in all circumstances of hyper-pressure. Finally, they must have a memory to make possible a reversibility as complete as possible. Moreover, it is necessary to mention the important anatomo-physiological role of the pelvic spaces ("potential spaces" of Anglosaxons), which designate plans that are easily removable during surgery, filled with connective and fatty tissues and which will ensure, despite the intimate relations between the various viscera, the functional interdependence of the three sectors, urinary, genital and digestive [3].

The dynamics and the pelvic statics depend, among other things, on the quality of the pelvic diaphragm formed by the elevating muscles of the anus and coccygians covered by the pelvic fascia and which constitutes a hammock spread transversely in the small pelvis which it separates in 2 floors: the superior floor or pelvic and the inferior floor or perineal. The parietal pelvic fascia covers the pelvic bony and muscular wall, spread between the posteroinferior border of the pubic symphysis anteriorly and the anterior surface of the last sacral vertebrae behind. Its peripheral edge joins the transversalis fascia while its medial edge continues with the visceral fascia. It is located a little above the plane of the lifts, slightly oblique at the bottom and in front. This parietal pelvic fascia presents tendinous reinforcements arranged according to the branches of a star (Roggie star) whose center is the sciatic spine. These areas of thickening are more resistant and are frequently used in reconstructive surgery pelvic static disorders for mooring fixation points or retaining material. The elevating muscle of the anus is the other essential element of this active support system. It is composed of 2 separate parts anatomically and functionally:

- A Lateral part: it is the sphincteric portion. This is a thin blade forming an oblique lean in which one individualizes 3 bundles, pubococcygien, iliococcygien and coccygien. The fibers converge towards the retroanal region, intermingle with those on the opposite side and then participate in the constitution of the anococcygeal raphe. During the MRI 
sequences, it is observed that this horizontal muscular plane is not plane but slightly convex upward, providing a vital role in supporting the pelvic organs (Figure 1).

- A paramedian part: it is the elevating portion. It is thicker, stronger and narrower than the outer part. Originating from the pelvis, it is described as a puborectal bundle that ends in the wall of the anal canal, and a pubovaginal tract that has intimate relations with the vagina and ends in the rectovaginal region. This muscular strap with anterior concavity delimits the uro-genitodigestive hiatus. It presents a basic tone that maintains the size of the hiatus at rest. Its reflex or voluntary contraction leads to the closing of the hiatus (ensuring the mechanisms of urinary and anal continence) whereas, on the other hand, its relaxation is essential to induce urination and defecation $[3,4]$.

During pregnancy, there is hormonal inflation that causes and / or aggravates previously undiagnosed prolapse. Ligament laxity increases during pregnancy. Genital prolapse seems to correlate with ligamentous hyperlaxity. Relaxin as a pregnancy hormone involved in connective tissue metabolism could lead to alteration of connective tissue that would be caused by pregnancy and would trigger the occurrence of genital prolapse [5].

\section{Risk factors}

\section{- Congenital factors}

\section{- Connective tissue abnormality}

Connective tissue abnormality could explain the existence of prolapse in the young nulliparous and even in the virgin. We find histological abnormalities of the tissue three times more frequently in women with genital prolapse than in other women [6].

\section{- Abnormality of the pelvis}

In certain configurations of the pelvis (reduced inclination of the superior strait, an increase of the sacred arrow, horizontalization of the pubic symphysis, opening of the pubic ogive), the constraints are exerted of advantages on the anterior perineum and in the axis of the urogenital cleft favoring the appearance of prolapse.

Nguyen found lumbar lordosis and horizontal pelvis in women with prolapse $[4,5]$.

\section{- Racial and family factors}

The white race appears as a risk factor for prolapse. Rinne has found a familial predisposition in women with prolapse [7].

\section{- Pregnancy and childbirth}

It is easy to understand that delivery, with the passage of the fetal mobile, can cause perineal lesions such as muscle pulling or stretching neuropathies that can lead to subsequent dysfunction. However, pregnancy itself is probably a risk factor. O'Boyle showed that the $P O P-Q$ stage increased significantly between the first and third trimesters of pregnancy [8]. This may be due to the hormonal impregnation that prepares the soft tissues at delivery, the stresses exerted on the perineum and the pelvic floor by the fetal weight; especially, as the axis of the pressures exerted is modified by the physiological tilting of the pelvis during pregnancy.

Childbirth has been mentioned as an issue of great importance. About $60 \%$ of patients with genital prolapse have had a health history of "difficult delivery" (forceps, complete perineal tear, delivery of macrosomia).

It seems that cesarean delivery is a protective factor compared to vaginal delivery $[4,6,8]$. Gyhagen et al., Found twice as much prolapse in vaginal delivery patients compared to caesarean patients, whether this caesarean section was scheduled or not Parity is a risk factor clearly identified in the literature $[8,9]$. Handa reports an increase of 1.4 odd ratio after each delivery [10]. In our patient this pauciparity can be incriminated.

\section{- Abdominal hyper pressure factors}

Obesity is a risk factor for genital prolapse [9]. Handa found abdominal circumference as a risk factor for prolapse but not body mass index (BMI). In his study, the increase in BMI was only associated with a higher risk of rectocele [8]. 
Gyhagen found that with each increase in one unit of BMI, the risk of symptomatic prolapse increased by $3 \%$ [9]. In our case, the BMl of our patient was $20 \mathrm{~kg} / \mathrm{m} 2$. Constipation as well as chronic pulmonary diseases could also be a risk factor for prolapse due to pushing efforts. One can imagine for the same reasons that a regular sporting activity, chronically soliciting the pelvic floor and the perineum, as well as certain professions, can be a risk factor of genital prolapse. However, this last risk factor is controversial [11,12].

\section{Complications}

\section{- Antepartum complications}

The loss of vaginal support during pregnancy in nulliparous women results in progressive uterine prolapse from stage 0 or I at the first trimester to stage I or II at the third trimester, which may be irreversible in the postpartum period. This is due to the physiological increase of progesterone and cortisol, which results in softening and stretching of the pelvic tissues, as well as physiological changes in pregnancy in terms of elongation and cervical hypertrophy. Nevertheless, pre-pregnancy prolapse is associated with spontaneous abortions and premature labor [13].

The main antepartum complication in pregnant women with prolapse is premature labor. Cervical edema due to obstruction and venous stasis and altered arterial blood circulation with subsequent anoxia may be the cause of the high incidence of abortions in these women, up to $15 \%$, as well as premature labor. The oedematous cervix is subject to mechanical trauma that can lead to ulceration and infection . Urinary tract infection, acute urinary retention and even maternal death have also been reported as complications of uterine prolapse during pregnancy. In our case, we noted an episode of urinary tract infection that caused a threat of preterm delivery [14].

\section{- Intra-partum complications}

The main intrapartum complications of uterine prolapse are dynamic dystocia due to cervical edema and a high rate of cervical laceration and. An inability or resistance of the cervix to dilate occurs, if the process is initiated outside the vaginal introit. The edema of the cervix adds a constraint to its fibrotic nature and can lead to cervical dystocia, which requires a cervical incision, a procedure that was previously used in a quarter of cases. In our patient, we found a surgical tear which was well repaired.

This prolonged cervical barrier has been reported to cause uterine rupture in the lower segment of the uterus. Fetal death and maternal morbidity are rarely reported $[13,14]$.

\section{- Postpartum complications}

In the past, puerperal infection was the main complication. In a study by Hill, on 170 pregnancies with uterine prolapse (1925-1940), fetal and maternal mortality rates during this period were $22.1 \%$ and $6.3 \%$, respectively. Persistent prolapse is associated with chronic cervicitis and sub-fertility due to the reduction in deposited sperm that remains adjacent to the cervix [13].

\section{Management of pregnancy and childbirth}

During pregnancy, bed rest in a moderate Trendelenburg position should be advised to reduce edema and displacement of the uterus [14]. Good genital hygiene is imperative and local antiseptics should be applied in case of ulceration or infection of the cervix [35]. In recent years, the use of pessary has been an important contribution in the management of genital prolapse. Several ways have been described and some arrangements must be made during installation [15].

The size of the pessary can be tested to be optimal at any time (before pregnancy and during pregnancy), as well as a specific followup during pregnancy, to check the good use of the pessary and the absence of complications (erosion, infection vaginal). The reduction of the prolapsed uterus will then protect the cervix from local trauma and prevent the possibility of incarceration. 
The risk of incarceration of the cervix in the pessary was mentioned in particular in studies conducted to evaluate the effectiveness of cervical pessaries, this risk should be avoided when the size of the pessary was adapted to the patient and when close monitoring is performed [16].

It is interesting to note a new laparoscopic option for the treatment of uterine prolapse, namely Gilliam's modified suspension, when other conservative solutions have not had therapeutic success. A laparoscopic uterine suspension has been described in early pregnancy. Laparoscopy, once feared and contraindicated in pregnancy, has been progressively accepted and applied, as evidenced by more and more reports published over the last decade [17]. Induction of labor with misoprostol and oxytocin should be avoided. Abdominal expression during pushing efforts could aggravate uterine prolapse and associated problems, namely edema, obstructed labor. This last action was the aggravating factor of prolapse in our patient.

The vaginal delivery is the mode of delivery most frequently reported in the literature.

It is recommended to women to prevent postpartum genital prolapse reduction of workload, and the eviction of the lifting of heavy objects during pregnancy and postpartum but especially the perineal rehabilitation of the postpartum [17].

\section{Conclusion}

Genital prolapse is a rare pathology during pregnancy. Knowledge of the pathophysiology is of vital interest. The use of the pessary considerably reduces the gravity. However, laparoscopic surgery is not contraindicated. Childbirth is the most reported in the literature.

\section{References}

1. Guariglia L. Uterine prolapse in pregnancy. Gynecol Obstet Invest $2005 ; 60: 192-4$.

2. Mohamed-Suphan N. Uterine prolapse complicating pregnancy and labor: a case report and littérature rewiew.Int Urogynecol $\mathrm{J}$ 2012; 23 :50.
3. DeLancey JO. The anatomy of the pelvic floor. Curr Opin Obstet

Gynecol 1994;6(4):313-6.

4. Kamina P, Chansigaud JP. [Support and suspension of the pelvic viscera in women. Functional and surgical anatomy]. J Gynecol.Obstet.Biol.Reprod.(Paris) 1988;17:835-48

5. Schauberger CW. Peripheral joint laxity incrase in pregnancy but does not correlate whith serum relaxin. Amm J Obstet Gynecol 1997 ; $174: 667-71$.

6. Jackson SR. Change in metabolism of collagen in genitourinary prolapse. Lancet $1996 ; 347$ : 466-75.

7. Rinne KM. What predispose young women to genital prolapse. Eur J Obstet Gynecol Reprod Biol 1999 84(1) : 23-5.

8. O'Boyle AL. Pelvic organ support in nulliparious pregnancy and nonpregnan women : a case control study. Am J Obstet Gynecol $2002 ; 187:$ 99-102.

9. Gyhagen M, Bullarbo M, Nielsen TF, Milsom I. Prevalence and risk factors for pelvic organ prolapse 20 years after childbirth: a national cohort study in singleton primiparae after vaginal or caesarean delivery BJOG 2013; 120 : 154-60.

10. Handa VL, Blomquist JL, Knoepp LR, Hoskey KA. Pelvic floor disorders 510 years after vaginal or cesarean childbirth Obstet Gynecol $2011 ; 118: 777-84$.

11. Kudish $\mathrm{BI}$, Iglesia $\mathrm{CB}$, Gutman RE, Sokol AI, Rodgers AK, Gass M. Risk factors for prolapse development in white, black, and Hispanic women Female Pelvic Med Reconstr Surg $2011 ; 17: 80-90$.

12. Tegerstedt G, Miedel A, MaehleSchmidt M, Nyren O, Hammarstrom M. Obstetric risk factors for symptomatic prolapse: a population based approach Am J Obstet Gynecol 2006 ; $194: 75-81$.

13. Gaetane J, Labriola BF. Prolapse of the uterus complicating pregnancy and labor; review and report of two cases. Obstet Gynecol 1956;8:278-83.

14. Sze EH, Sherard GB III, Dolezal JM. Pregnancy, labor, delivery, and pelvic organ prolapse. Obstet Gynecol 2002;100:981-6.

15. Swift S, Woodman P, O'Boyle A, Kahn M, Valley M, Bland D, et al. Pelvic Organ Support Study (POSST): the distribution, clinical definition, and epidemiologic condition of pelvic organ support defects Am J Obstet Gynecol 2005 ; 192 : 795-806. 
Biaye B et al., IRJOG, 2019 2:9

16. Tukur J, Omale AO, Abdullahi H, Datti Z. Uterine prolapse following fundal pressure in the first stage of labour: a case report. Ann Afr Med 2007;6:194-6.

17. Jackson H, Granger S, Price R, et al. Diagnosis and laparoscopic treatment of surgical diseases during pregnancy: an evidencebased review. Surg Endosc 2008;22:1917-27.

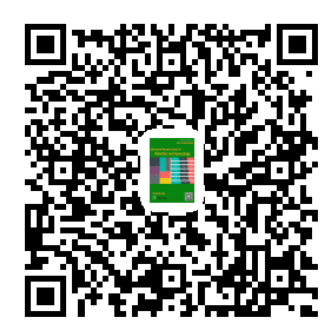

